\title{
Distributed Revisiting: An Analytic for Retention of Coherent Science Learning
}

\author{
Vanessa Svihla and Michael J. Wester \\ University of New Mexico, Albuquerque, USA \\ vsvihla@unm.edu \\ Marcia C. Linn \\ University of California, Berkeley, USA
}

\begin{abstract}
Designing learning experiences that support the development of coherent understanding of complex scientific phenomena is challenging. We sought to identify analytics that can also guide such designs to support retention of coherent understanding. Based on prior research that distributing study of material over time supports retention, we explored revisiting previously studied material as an analytic. We tested ways to operationalize revisiting: as a general propensity to revisit previously studied material; as a propensity to revisit specific curricular steps; as a general propensity to distribute study by revisiting previously studied material on different days; and as a propensity to distribute study by revisiting specific steps on different days. The specific steps identified as central to the learning design included a static illustration and a dynamic visualization. We modelled revisiting in a sample of 664 students taught by seven different teachers using a Web-based Inquiry Science Environment unit. Analysis of log files and regression modelling revealed that a general propensity to revisit did not predict retention. Revisiting the dynamic visualization better supported retention than revisiting static material, but only for distributed revisiting. Our findings suggest that revisiting can be a useful analytic when aligned with the framework guiding learning design.
\end{abstract}

Keywords: Learning design, revisiting, distributed practice, knowledge integration, inquiry science

Editor's Note: As part of the Special Section on Learning Analytics \& Learning Theory this article is followed by a short commentary on pp. 102-106 that discusses the challenges it faced and successes it achieved in drawing on and contributing to theory use in learning analytics.

\section{RATIONALE}

Lockyer, Heathcote, and Dawson (2013) suggest a symbiotic relationship between learning design and learning analytics, with the former providing a lens to understand pedagogical aims and the latter as evidence that can be used to evaluate the design; this approach is compelling because data are collected passively and in-situ. The learning design necessarily informs the pedagogical aims, as without this, deciphering the relevance of particular data signals is challenging. As a result, much of learning analytics has focused on student progress and time spent on a task. 
There is evidence that spending more time on task can support learning and retention (Barbera \& Reimann, 2013; Cotton, 1990). Using amount of time as a metric for learning is appealing because it is relatively easy to measure. However, what students do during time spent studying also matters. To develop a more nuanced metric, we consider findings from studies of distributed practice, one of the most well-documented findings from laboratory studies of recall; numerous studies show that restudy of material, distributed in time, supports learning (Cepeda, Pashler, Vul, Wixted, \& Rohrer, 2006; Delaney, Verkoeijen, \& Spirgel, 2010; Donovan \& Radosevich, 1999; Janiszewski, Noel, \& Sawyer, 2003). In this study, we explore the metric of revisiting - how and what students spontaneously revisit in inquiry science materials - and how it relates to their retention. We specifically explore ways revisiting can be a useful analytic for guiding the design of technology-enhanced learning experiences when retention of coherent understanding of complex scientific phenomena is the learning goal. This responds to calls for learning analytics to guide learning design (Ferguson, 2012).

\section{LITERATURE REVIEW}

We begin by discussing the Knowledge Integration framework that guided our learning design (Figure 1). We review literature on distributed practice to explain why we sought revisiting as a relevant metric for retention. We then discuss research on static and dynamic visualizations for learning inquiry science, as we compare these as targets for students' spontaneous revisiting in web-based learning environments.

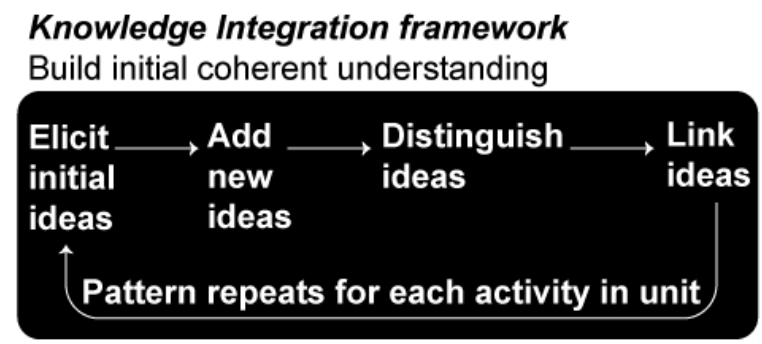

Knowledge Integration framework Build initial coherent understanding

$\begin{aligned} & \text { Elicit } \longrightarrow \text { Add } \\ & \text { initial } \\ & \text { ideas }\end{aligned} \quad \begin{aligned} & \text { new } \\ & \text { ideas }\end{aligned}$
\[ \begin{array}{l}\text { Distinguish } \\ \text { ideas }\end{array} \]
Pattern repeats for each activity in unit

\section{can directly revisit different steps within an activity. \\ 2.1 Knowledge Integration Framework Guiding Learning Design}

Figure 1. Model for retention of coherent understanding of complex phenomena, informed by the Knowledge Integration framework and research on distributed practice. The left-hand figure represents a single activity within a unit. In the right-hand figure, the arrows indicate that students

We use the term learning design (Laurillard, 2012; Lockyer et al., 2013) to describe the pedagogical approach - Knowledge Integration - instantiated in a Web-based Inquiry Science Environment (WISE) (Slotta \& Linn, 2009) unit. Learning designs aim to be reusable or adaptable across contexts, and WISE 
(2015). Revisiting for retention: An analytic for inquiry science learning. Journal of Learning Analytics, 2(2), 75-101. http://dx.doi.org/10.18608/jla.2015.22.7

units accomplish this by providing professional development for teachers and providing tools that allow teachers to adapt units for their classrooms; this adaptation commonly continues into the classroom as teachers implement units differently, with some teachers weaving other resources, quizzes, labs, and activities into the unit, and others taking a guiding role, offering additional instruction only when students seek help. WISE units provide guidance to teachers and students about what they should do and when to do it, and the resources required to carry out the activities, which are primarily simulationbased.

The Knowledge Integration framework (Kali, 2006; Linn \& Eylon, 2011) draws on extensive classroom research to identify ways to guide students to integrate their diverse and often conflicting ideas about core themes, such as energy transfer and transformation across science disciplines (Svihla et al., 2010). We refer to the process by which students develop a coherent understanding of science that involves generating ideas, adding new ideas, comparing and distinguishing their new and prior ideas, and linking relevant, normative ideas together, as knowledge integration (Kali, Linn, \& Roseman, 2008).

WISE units scaffold students using an inquiry map (Figure 2) to support them in developing coherent understanding of science ideas (Linn, 2006). Each unit comprises activities of multiple steps (listed along the left side). Activities first elicit students' ideas. Next, activities introduce students to new ideas (commonly described in the Knowledge Integration framework as "adding ideas"). Finally, activities help students distinguish and evaluate between their initial ideas and newly added ideas. In many activities, this is accomplished through sequences in which students make predictions, interact with dynamic visualizations, then reflect on their observations. For instance, in the unit called Global Climate Change (GCC) (Svihla \& Linn, 2012a), students learn about the greenhouse effect and the role of energy transfer and energy transformation in climate change. They investigate NetLogo visualizations (Wilensky \& Reisman, 2006) representing the earth and atmosphere, and variables involved in climate change.

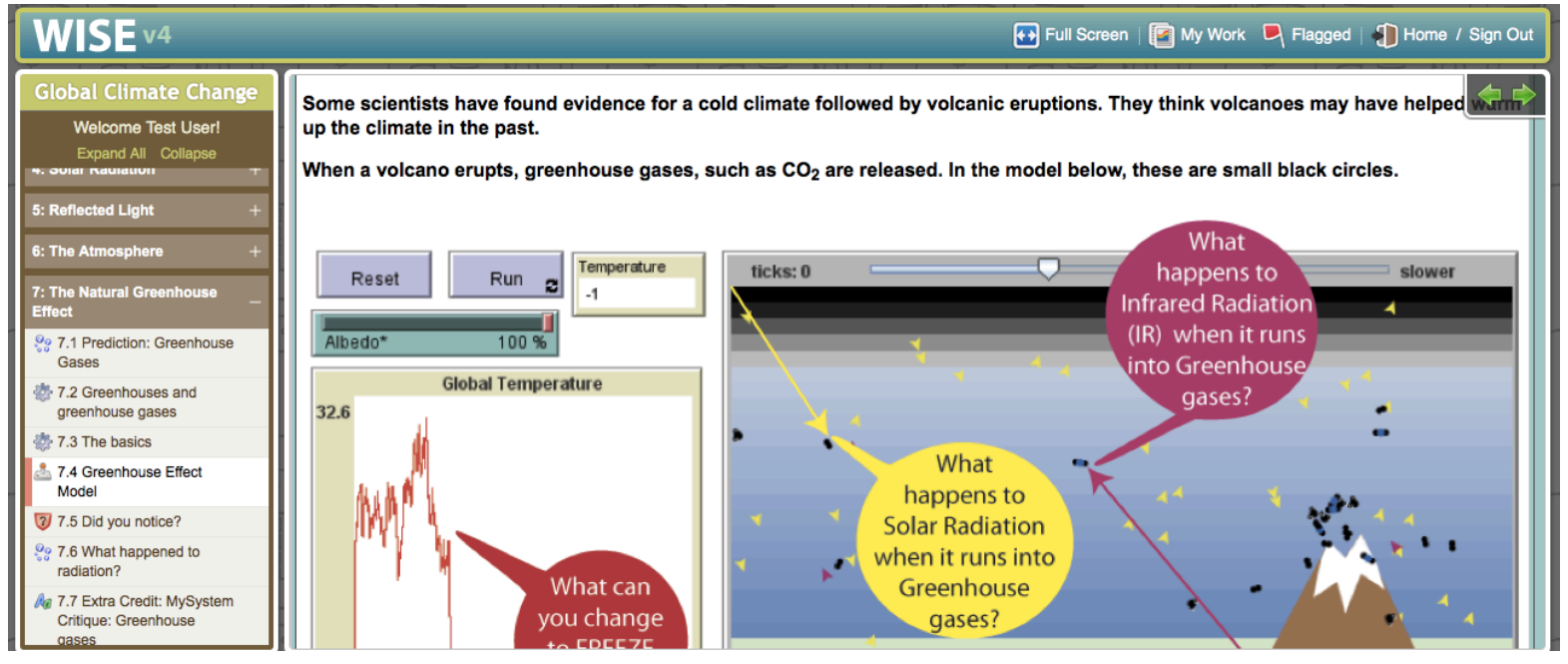

Figure 2. Inquiry map for the WISE 4 environment. Activities five through seven are visible; activity seven is expanded to show it comprises seven steps. 
(2015). Revisiting for retention: An analytic for inquiry science learning. Journal of Learning Analytics, 2(2), 75-101. http://dx.doi.org/10.18608/jla.2015.22.7

Using the inquiry map, students can revisit prior steps throughout the unit; this is part of the learning design, as one goal of the knowledge integration framework is to promote the ability of students to monitor their own learning by knowing when they need more information (Chiu, 2010). More generally, recognizing the value of revisiting is consistent with recognizing the need to stop and explain a text to oneself, a process called "generating self-explanations" (Chi, Bassok, Lewis, Reimann, \& Glaser, 1989). Some research suggests that students are able to judge when it is advantageous to distribute their learning over time (Popham, 2009). However, studies of self-explanation show that some students spontaneously seek to explain conundrums while others do not (Slotta \& Chi, 2006) and that individuals differ in their propensity to update their memories (Bjork, 1978). For this reason, some authors of WISE units structure revisiting, such as by forcing students to revisit earlier steps based on non-normative responses. However, understanding students' spontaneous revisiting patterns and their relationship to retention of coherent understanding could help guide learning designs beyond simple checks. For instance, prior research has demonstrated that distributing study over time better supports retention; thus, understanding how students revisit steps over time could guide new design patterns that better support retention.

\subsection{Revisiting as Distributed Practice to Support Retention}

\subsubsection{Revisiting as Distributed Practice Supports Learning}

Students might revisit a step to help clarify their ideas, making revisiting a form of distinguishing ideas, as advocated in the knowledge integration framework (Svihla \& Linn, 2012b; Zhang \& Linn, 2011). However, revisiting could also be unproductive, as when students reread text, adding multi-coloured underlining but not gaining more insight into the material (Bjork \& Bjork, 2009). There are many reasons why a student might decide to revisit a step; yet, any revisiting provides an opportunity to restudy. Thus, a general propensity to revisit previously studied material could confer an advantage for retention.

Students develop more durable, integrated understanding when they distribute their study in time, rather than when they mass their practice. For instance, consider two students studying for a chemistry test. Diego reviews the material for 10 minutes each day, for seven days. Mario reviews the material for 70 minutes the day before the test. Hundreds of studies (e.g., as reviewed in Cepeda et al., 2006; Delaney et al., 2010; Donovan \& Radosevich, 1999; Janiszewski et al., 2003) would predict Diego will do better on the exam because he distributed his study over time. These findings held for repetition and induction tasks (Kornell, Castel, Eich, \& Bjork, 2010) and abstraction and generalization tasks (West, 2011). Classroom studies and studies with educationally relevant materials have recently become more common, finding benefits to distributed study of scientific prose (Roediger \& Karpicke, 2006), maps (Carpenter \& Pashler, 2007), history facts (Carpenter, Pashler, \& Cepeda, 2009), vocabulary (Bloom \& Shuell, 1981; Seabrook, Brown, \& Solity, 2005; Sobel, Cepeda, \& Kapler, 2010), multiplication facts (Rea \& Modigliani, 1985), statistics concepts (Budé, Imbos, Wiel, \& Berger, 2011; Smith \& Rothkopf, 1984), 
(2015). Revisiting for retention: An analytic for inquiry science learning. Journal of Learning Analytics, 2(2), 75-101. http://dx.doi.org/10.18608/jla.2015.22.7

middle school biology concepts (Reynolds \& Glaser, 1964), university medical education (Kerfoot, Kearney, Connelly, \& Ritchey, 2009), and elementary science (Vlach \& Sandhofer, 2012).

However, many of these studies occurred over a relatively short period, raising the need for further research under real-world and longer timeframe conditions (Cepeda et al., 2006; Dunlosky \& Rawson, 2012). Partially taking up these concerns, recent research has documented the utility and generality of learning analytics approaches to distributed practice, finding, for instance, that learning management systems can provide usable information about distributed practice (Andergassen, Mödritscher, \& Neumann, 2014; Mödritscher, Andergassen, \& Neumann, 2013). These studies show that distributing study across time and over days supports learning for a range of topics, particularly when students are able to integrate ideas across a course of study (Andergassen et al., 2014). However, questions still remain about how to support students to revisit previously studied content effectively to lead to retention of integrated understanding, which may depend on more than simple revisiting to recall previously studied material (Dunlosky \& Rawson, 2012).

\subsection{Retention of Integrated Understanding}

Researchers have varied the length of time between the final study session and the delayed post-test called the retention interval (Carpenter, Cepeda, Rohrer, Kang, \& Pashler, 2012). Several studies of retention have produced reversal effects from immediate post-test to delayed post-test (Bird, 2010; Rawson, 2012; Rawson \& Kintsch, 2005). In these studies, distributed study sessions do not appear to benefit performance on the immediate post-test, but they do on delayed post-tests. For instance, in a study involving calculating the number of permutations for sequences, students first learned how to do a problem, and then either completed ten practice problems in one clustered session or in two sessions one week apart. Post-test results showed no difference, but the delayed post-test given four weeks later showed greater retention for those in the distributed group (Rohrer \& Taylor, 2006).

Likewise, in a study of expository texts contrasting a massed condition with a distributed condition with a one-week gap between activities, an advantage was found after a longer retention interval. Students were tested for reading comprehension either immediately upon completion or after a two-day retention interval (Rawson \& Kintsch, 2005). Those in the massed condition performed better on the immediate test, but those in the distributed condition performed better after a two-day retention interval. To explain why this might occur, researchers explored whether the long or short retention interval would lead to more integrated ideas (Rawson, 2012). Rawson tested this idea by focusing on specific post-test question types (free and cued recall), predicting that longer gaps between study sessions and a longer retention interval would depend "more heavily on the degree of integration" (Rawson, 2012, p. 873). Analysis showed that participants with longer gaps between study sessions were likelier to recall the main and important ideas over the unimportant ideas. The students experiencing a 
(2015). Revisiting for retention: An analytic for inquiry science learning. Journal of Learning Analytics, 2(2), 75-101. http://dx.doi.org/10.18608/jla.2015.22.7

longer retention interval performed significantly higher on the cued recall questions by recalling more ideas after the delay.

Thus, the benefits of revisiting previously studied material might not show up on immediate post-tests. A delayed post-test is likelier to detect the potential benefit of distributed study. This presents a potential challenge to the design of adaptive learning systems, unless retention is a priority of the designers.

\subsection{Revisiting What?}

While we cannot always detect why students choose to revisit previously studied material, we can easily explore what they revisit, and test revisiting as a diagnostic for retention of coherent understanding. WISE units include various curricular step types, such as text, static illustrations, and dynamic visualizations.

Based on prior research, we know that students can learn about abstract or invisible phenomena - like heat transfer and transformation - from dynamic visualizations (e.g., Cook, 2006; Marbach-Ad, Rotbain, \& Stavy, 2008). While there is continued controversy about how and when static versus dynamic visualizations support learning (Tversky, Morrison, \& Betrancourt, 2002), there is substantial support for their use in learning (Höffler \& Leutner, 2007), particularly when student interactions with visualizations are scaffolded (Hegarty, 2004; Tversky et al., 2002). In our prior research, we have found that students do learn from dynamic visualizations designed to support knowledge integration (Ryoo \& Linn, 2010, 2012; Svihla \& Linn, 2012a). This typically means that students are first asked to make predictions, interact with a dynamic visualization, and then reflect on what they learned.

When supporting students to learn about a complex phenomenon, we have also added static illustrations to help students connect their prior experiences to the phenomenon and notice salient features when they interact with the dynamic visualizations. For instance, in the Global Climate Change unit, we added a static illustration (Figure 3, left) prior to the dynamic visualization (Figure 3, right). This was added based on analysis of video data and log file data from initial testing of the learning design.

This combination supported the initial development of coherent understanding of climate change and energy transformation as an important mechanism for the greenhouse effect (Svihla \& Linn, 2012a); here we explore how students' spontaneous revisiting of these relates to retention of this understanding. 
(2015). Revisiting for retention: An analytic for inquiry science learning. Journal of Learning Analytics, 2(2), 75-101. http://dx.doi.org/10.18608/jla.2015.22.7
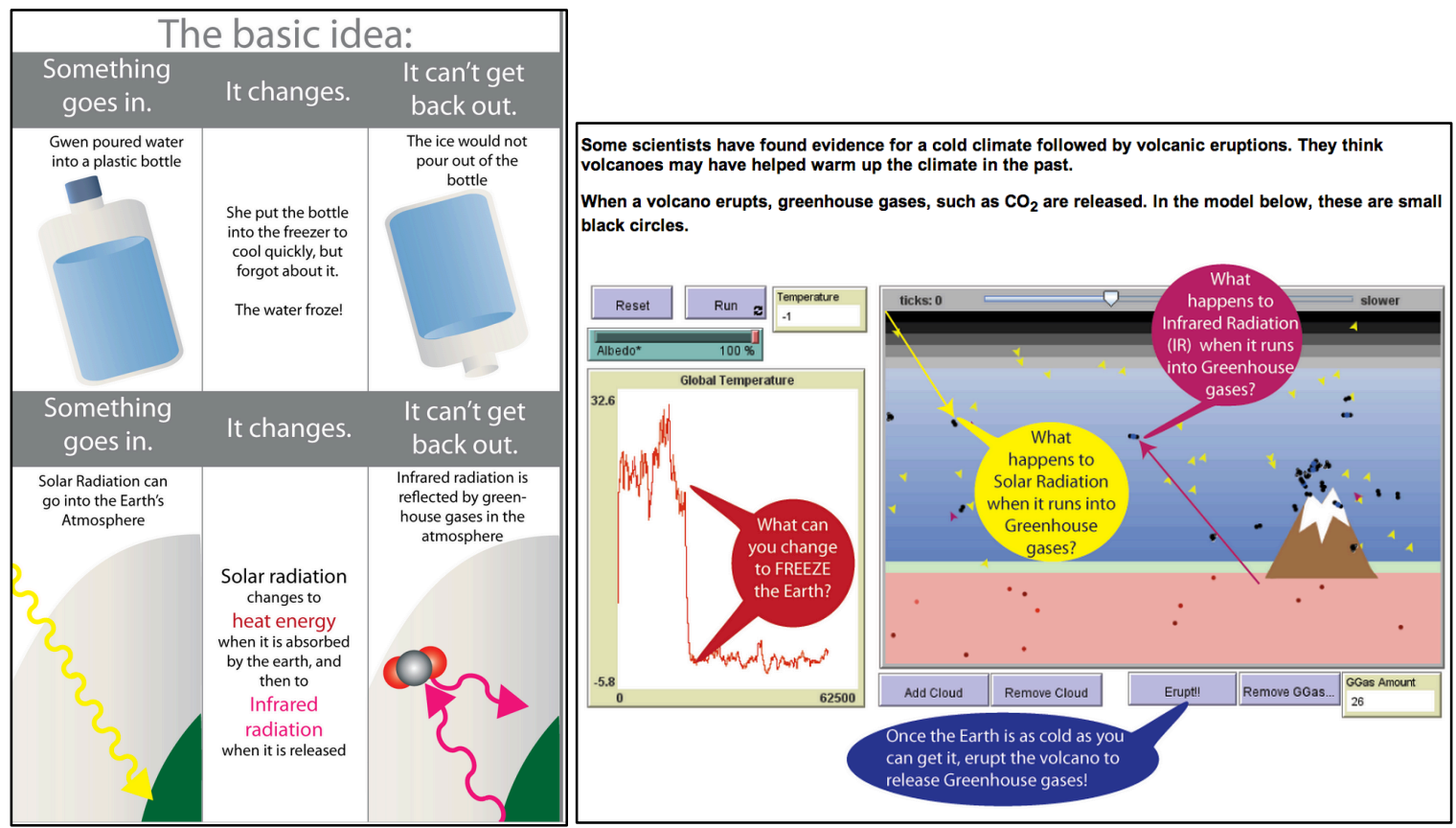

Figure 3. On left, the static curriculum step in which students see a simple metaphor for energy transformation as an advance organizer. On the right, a dynamic visualization step, in which students first see a screenshot suggesting various experiments and then can test out their own ideas with the visualization.

The static illustration contains information about energy transformation in the greenhouse effect and compares it to phase changes in water. The dynamic visualization contains information about energy transformation in the greenhouse effect, and additionally allows students to relate this to global temperature. In contrast to the static illustration, the information is not presented directly; students must explore the visualization to uncover this information. Thus, the dynamic visualization contains more information than the static illustration, but the information is available only through interaction with the dynamic visualization.

\section{RESEARCH PURPOSE}

We investigated students' spontaneous revisiting of prior steps as a form of self-distributed learning. We tested various types of revisiting of earlier steps in the unit with a large sample of students taught by several teachers. We also examined duration of instruction. We investigated the following questions:

1. How does duration of instruction explain variance in retention of integrated knowledge?

2. How do duration of instruction and specific ways to operationalize revisiting as an analytic explain variance in retention of integrated knowledge, with revisiting defined as propensity to:

a) revisit prior steps in general; 
(2015). Revisiting for retention: An analytic for inquiry science learning. Journal of Learning Analytics, 2(2), 75-101. http://dx.doi.org/10.18608/jla.2015.22.7

b) revisit specific steps - a static illustration or a dynamic visualization;

c) distribute study in general by revisiting steps across days;

d) distribute study by revisiting specific steps - a static illustration or a dynamic visualization across days.

We hypothesized that propensity to distribute study by revisiting specific steps would best predict retention. We further predicted that restudy of the more complex dynamic visualization would better support retention. Operationalizing revisiting in this way best aligns to our learning design.

\section{METHODS}

\subsection{Instructional Materials}

Students studied a previously tested WISE unit called Global Climate Change (GCC) (Svihla \& Linn, 2012a). This unit teaches students about the greenhouse effect and the role of energy transfer and energy transformation in climate change.

\subsection{Participants}

Participants were 835 grade 6 students ( 664 students completed all measures) taught by seven different teachers at three culturally diverse middle schools. All teachers taught the unit in five to seven consecutive class periods.

Data were collected during two consecutive school years. Each teacher was assigned an ID (Table 1). Three teachers provided data for both years. Three of the teachers taught multiple class periods per day, resulting in larger sample sizes for those teachers. We define an implementation as including all class periods taught by a teacher in a given semester. In total, ten implementations are included in the study, with three teachers contributing two implementations. Mean total time spent studying the unit ranged from 133 to 301 minutes.

\subsection{Assessments}

We used Knowledge Integration assessments aligned with the unit. The assessment items have been shown to have good psychometric properties and to be valid indicators of knowledge integration (Liu, Lee, Hofstetter, \& Linn, 2008; Liu, Ryoo, Linn, Sato, \& Svihla, 2015). Retention was measured using a delayed post-test $(M=12.88, S D=2.06)$ administered a mean of 23 days following instruction (Table 1). Teachers gave the delayed post-test to fit their particular schedules, resulting in retention intervals that varied from 4 to 40 days. The delayed post-test included six Knowledge Integration items (maximum possible score of 21) drawn from a longer assessment that additionally covered other topics as part of a project investigating cumulative learning (Liu et al., 2015; Svihla et al., 2010). The items included in the 
(2015). Revisiting for retention: An analytic for inquiry science learning. Journal of Learning Analytics, 2(2), 75-101. http://dx.doi.org/10.18608/jla.2015.22.7

delayed post-test assessed students' understanding of energy transfer by radiation, energy transformation, and the role energy transformation plays in the greenhouse effect; these same concepts are taught in the curriculum steps in Figure 3. The delayed post-test scores appear relatively low in part because energy transfer and transformation were challenging items, intended to detect growth over multiple years.

Table 1. Descriptive statistics for each implementation, including retention interval, delayed post-test

\begin{tabular}{cccccccc}
\multicolumn{7}{c}{ scores, and total minutes spent on the unit } \\
\hline Year & Teacher ID & $\begin{array}{c}\text { Retention } \\
\text { interval } \\
\text { (days) }\end{array}$ & $\mathrm{n}$ & \multicolumn{3}{c}{$\begin{array}{c}\text { Delayed Post-test } \\
\text { score }\end{array}$} & Total minutes \\
\hline 2010 & 0 & 31 & 79 & 14.44 & 2.64 & 215.73 & 24.67 \\
2010 & 1 & 17 & 28 & 15.00 & 2.80 & 229.69 & 36.38 \\
2010 & 2 & 15 & 60 & 13.45 & 2.59 & 187.23 & 48.07 \\
2010 & 3 & 23 & 27 & 13.89 & 3.07 & 184.19 & 21.11 \\
2011 & 0 & 4 & 93 & 12.19 & 1.66 & 205.06 & 45.66 \\
2011 & 1 & 12 & 52 & 13.02 & 1.59 & 300.75 & 68.94 \\
2011 & 2 & 26 & 91 & 12.36 & 1.42 & 235.73 & 59.19 \\
2011 & 4 & 24 & 26 & 12.31 & 1.19 & 222.47 & 49.43 \\
2011 & 5 & 15 & 26 & 12.04 & 1.08 & 95.78 & 17.90 \\
2011 & 6 & 40 & 182 & 12.36 & 1.26 & 132.62 & 25.24 \\
\hline
\end{tabular}

\section{$5 \quad$ ANALYSIS}

\subsection{Data Coding}

Student responses were saved by the WISE4 system and scored using validated Knowledge Integration rubrics (Svihla \& Linn, 2012a). Two raters coded a subset of items; any discrepancies were discussed until consensus was reached. To be successful on Knowledge Integration items, students must exhibit a coherent, connected, normative understanding (Table 2). Note that because the lowest possible score per question is 1 , tests containing multiple questions have a minimum score equal to the number of items (as opposed to 0). 
(2015). Revisiting for retention: An analytic for inquiry science learning. Journal of Learning Analytics, 2(2), 75-101. http://dx.doi.org/10.18608/jla.2015.22.7

Table 2. Knowledge Integration scores, levels, and descriptions

\begin{tabular}{|c|c|c|}
\hline $\begin{array}{l}\text { Knowledge } \\
\text { Integration } \\
\text { score }\end{array}$ & Level & Description \\
\hline 1 & Irrelevant & $\begin{array}{l}\text { Does not answer the question being asked, or chose not to } \\
\text { answer }\end{array}$ \\
\hline 2 & Non-normative & $\begin{array}{l}\text { Contains non-normative ideas or links, vague ideas, or } \\
\text { scientifically invalid connections between ideas }\end{array}$ \\
\hline 3 & Partial link & $\begin{array}{l}\text { Unelaborated connections using relevant features OR } \\
\text { Scientifically valid connections not sufficient to solve the } \\
\text { problem. }\end{array}$ \\
\hline 4 & Full link & One scientifically complete and valid connection \\
\hline 5 & Complex link & Two or more scientifically complete and valid connections \\
\hline
\end{tabular}

\subsection{Log File Analysis}

The WISE system logs student progress through units, providing timestamps of the students' activity in sequence in an exportable Excel file (Figure 4). All student dyads associated with a teacher's implementation are exported into a single file. To reliably document student revisiting, we used an Applescript (excel2csv.app) to extract student logs into individual .csv files. We then used MATLAB to extract data about revisiting patterns and timing. This process resulted in a .csv file for each teacher's implementation.

\begin{tabular}{|c|c|c|c|c|c|}
\hline Step Title & Step Type & Step Prompt & Start Time & End Time & Time Student Work \\
\hline 11.1 Introduction & $\mathrm{Html}$ & N/A & 2010-05-06 16:27:06.0 & $2010-05-06$ 16:27:41.0 & $35 \mathrm{~N} / \mathrm{A}$ \\
\hline 21.2 Pre: Car on cc & Assessmen & $t$ At the end of the & 2010-05-06 16:27:41.0 & 2010-05-06 16:30:22.0 & 161 Warmer than $t$ \\
\hline 3 1.3 Pre: Burning & Assessmen & Note: At the end & (2010-05-06 16:30:22.0 & 2010-05-06 16:34:36.0 & 254 Lower relative \\
\hline 4 1.4 Pre: Advise G & A Assessmen & $\mathrm{t}<\mathrm{p}>$ Note: At the & e2010-05-06 16:34:36.0 & 2010-05-06 16:38:54.0 & 258 Turn off compt \\
\hline 5 1.5 MySystem Ins & $\mathrm{t} \mathrm{Html}$ & N/A & $2010-05-06 \quad 16: 38: 54.0$ & 2010-05-06 16:39:26.0 & $32 \mathrm{~N} / \mathrm{A}$ \\
\hline 6 1.6 Pre: MySyster & rMySystem & & 2010-05-06 16:39:26.0 & 2010-05-06 16:39:44.0 & $18 \mathrm{~N} / \mathrm{A}$ \\
\hline 71.5 MySystem Ins & $\mathrm{tHtml}$ & N/A & 2010-05-06 16:39:44.0 & $2010-05-06$ 16:39:54.0 & $10 \mathrm{~N} / \mathrm{A}$ \\
\hline 8 1.6 Pre: MySyster & rMySystem & & 2010-05-06 16:39:54.0 & 2010-05-06 16:42:36.0 & $162 \mathrm{~N} / \mathrm{A}$ \\
\hline 9 1.5 MySystem Ins & $\mathrm{t} \mathrm{Html}$ & N/A & $2010-05-06$ 16:42:36.0 & 2010-05-06 16:42:44.0 & $8 \mathrm{~N} / \mathrm{A}$ \\
\hline 10 1.6 Pre: MySyster & MySystem & & 2010-05-06 16:42:44.0 & 2010-05-06 16:43:14.0 & $30 \mathrm{~N} / \mathrm{A}$ \\
\hline 11 1.5 MySystem Ins & $\mathrm{t} \mathrm{Html}$ & N/A & 2010-05-06 16:43:14.0 & 2010-05-06 16:43:19.0 & $5 \mathrm{~N} / \mathrm{A}$ \\
\hline 12 1.6 Pre: MySyster & rMySystem & & 2010-05-06 16:43:19.0 & 2010-05-06 16:43:21.0 & $2 \mathrm{~N} / \mathrm{A}$ \\
\hline 131.5 MySystem Ins & $\mathrm{t} \mathrm{Html}$ & N/A & 2010-05-06 16:43:21.0 & 2010-05-06 16:43:24.0 & $3 \mathrm{~N} / \mathrm{A}$ \\
\hline 14 1.6 Pre: MySyster & MySystem & & 2010-05-06 16:43:24.0 & 2010-05-06 16:44:43.0 & $79 \mathrm{~N} / \mathrm{A}$ \\
\hline 151.5 MySystem Ins & $\mathrm{t} \mathrm{Html}$ & N/A & 2010-05-06 16:44:43.0 & 2010-05-06 16:44:47.0 & $4 \mathrm{~N} / \mathrm{A}$ \\
\hline 16 1.6 Pre: MySyster & MySystem & & $2010-05-06$ 16:44:47.0 & 2010-05-06 16:45:03.0 & $16 \mathrm{~N} / \mathrm{A}$ \\
\hline 17 1.5 MySystem Ins & $\mathrm{t} \mathrm{Html}$ & N/A & 2010-05-06 16:45:03.0 & 2010-05-06 16:45:07.0 & $4 \mathrm{~N} / \mathrm{A}$ \\
\hline 18 1.6 Pre: MySyster & MySystem & & 2010-05-06 16:45:07.0 & 2010-05-06 16:45:54.0 & $47 \mathrm{~N} / \mathrm{A}$ \\
\hline 19 1.6 Pre: MySyster & rMySystem & & $2010-05-07$ 12:45:51.0 & 2010-05-07 12:46:55.0 & $64 \mathrm{~N} / \mathrm{A}$ \\
\hline 201.5 MySystem Ins & $\mathrm{tH} \mathrm{tml}$ & N/A & $2010-05-07$ 12:46:55.0 & 2010-05-07 12:47:03.0 & $8 \mathrm{~N} / \mathrm{A}$ \\
\hline 21 1.6 Pre: MySyster & MySystem & & $2010-05-07$ 12:47:03.0 & 2010-05-07 12:47:16.0 & $13 \mathrm{~N} / \mathrm{A}$ \\
\hline 22 1.5 MySystem Ins & $\mathrm{t} \mathrm{Html}$ & N/A & $2010-05-07$ 12:47:16.0 & $2010-05-07$ 12:47:20.0 & $4 \mathrm{~N} / \mathrm{A}$ \\
\hline
\end{tabular}

Figure 4. Screenshot of an Excel workbook containing log file data from one teacher's implementation of the Global Climate Change unit.

The first column in the spreadsheet provides the sequence (Figure 4). The second column identifies the number and title of the step the dyad visited. The third and fourth columns provide information about 
(2015). Revisiting for retention: An analytic for inquiry science learning. Journal of Learning Analytics, 2(2), 75-101. http://dx.doi.org/10.18608/jla.2015.22.7

the step type and prompts. The fifth, sixth, and seventh columns provide time and date information about each visit. The eighth column shows student work, making it possible for researchers to identify when students made changes to their answers.

Thus, several variables are easily computed. We computed the total time (duration of study) each dyad spent on the unit. To explore revisiting, we computed several variables (Tables 3 and 4). We first eliminated visits lasting less than five seconds since these generally resulted from students clicking the "Next" or "Back" buttons in rapid succession. Rapid clicking was also observed during classroom observations and in videos of implementation when students quickly clicked through steps to reach a desired step.

Based on past research showing that students differ in their propensity to update their memories (Bjork, 1978), we computed a revisiting disposition variable, defined as the average number of visits made to steps across the unit (Tables 3 and 4). Thus, if a dyad visited every step in the unit twice, they would receive a score of two.

We also hypothesized that while students differ in propensity to update their memories, they could also differ in what they chose to revisit. We viewed the specific curriculum steps in Figure 3 as likely targets of restudy based on classroom observations. These two steps in particular are the central focus of the unit. They also provide an interesting contrast. Previous studies of dynamic visualizations embedded in WISE units have provided evidence that students often learn more from them compared to static illustrations. We anticipated differences when dyads revisited one or the other because of differences in the type of step (dynamic versus static) and the amount of information in each step (both contained information about the role of energy transformation in the greenhouse effect, but only the dynamic visualization related that to changes in global temperature). We calculated variables for the total number of visits to each of these steps.

Based on past research, we also wanted to test the benefit for longer lags between revisits. For instance, based on a meta-analysis, longer intervals between study sessions better support more complex tasks (Donovan \& Radosevich, 1999). This suggests that immediate revisits (e.g., those occurring on the same day) to recently viewed materials may not lead to longer retention of coherent understanding. Thus, we computed a distributed disposition variable based on the number of days each dyad visited each step. This was calculated as the average number of days students visited each step throughout the unit. Students who visited each step on one and only one day would have a score of one, whereas those who visited each step on two days would have a score of two.

We also computed distributed visit variables for the same specific steps - the dynamic visualization and the static illustration. We predicted an advantage when students visited these steps on more than one day because the visits would be more distributed in time. 
(2015). Revisiting for retention: An analytic for inquiry science learning. Journal of Learning Analytics, 2(2), 75-101. http://dx.doi.org/10.18608/jla.2015.22.7

Table 3. Variables computed to explore revisiting

\begin{tabular}{|c|c|c|}
\hline visiting & lated as & ation \\
\hline $\begin{array}{l}\text { Revisiting disposition: } \\
\text { General disposition to } \\
\text { revisit }\end{array}$ & $\begin{array}{l}\text { Calculated as average number of } \\
\text { visits across all steps. Both same- } \\
\text { day and across-day visits to a step } \\
\text { counted. }\end{array}$ & $\begin{array}{l}\text { Students differ in their propensity } \\
\text { to update their memories (Bjork, } \\
\text { 1978). }\end{array}$ \\
\hline $\begin{array}{l}\text { Number of visits to } \\
\text { static illustration. }\end{array}$ & $\begin{array}{l}\text { mber of } \\
\text { m step. }\end{array}$ & \multirow{2}{*}{$\begin{array}{l}\text { Students vary in propensity to } \\
\text { update their memories (Bjork, } \\
\text { 1978), but what they choose to } \\
\text { revisit could correspond to what } \\
\text { they retain. }\end{array}$} \\
\hline $\begin{array}{l}\text { Number of visits to } \\
\text { dynamic visualization. }\end{array}$ & $\begin{array}{l}\text { as the total number of } \\
\text { e dynamic visualization. }\end{array}$ & \\
\hline $\begin{array}{l}\text { Distributing disposition: } \\
\text { Disposition to revisit } \\
\text { steps across days }\end{array}$ & $\begin{array}{l}\mathrm{d} \text { as average number of } \\
\text { ad visited each step. }\end{array}$ & $\begin{array}{l}\text { Students can judge when it is } \\
\text { advantageous to distribute their } \\
\text { learning over time (Popham, } \\
\text { 2009). }\end{array}$ \\
\hline $\begin{array}{l}\text { Number of days visited } \\
\text { static illustration }\end{array}$ & $\begin{array}{l}\text { Calculated as the total number of } \\
\text { days a dyad visited the static } \\
\text { illustration. }\end{array}$ & \multirow{2}{*}{$\begin{array}{l}\text { Students can judge when it is } \\
\text { advantageous to distribute their } \\
\text { learning over time (Popham, } \\
\text { 2009), but what they choose to } \\
\text { revisit could correspond to what } \\
\text { they retain. }\end{array}$} \\
\hline $\begin{array}{l}\text { Number of days visited } \\
\text { dynamic visualization }\end{array}$ & $\begin{array}{l}\text { Calculated as the total number of } \\
\text { days a dyad visited the dynamic } \\
\text { visualization. }\end{array}$ & \\
\hline
\end{tabular}

Table 4. Descriptive statistics for each type of revisiting variable

\begin{tabular}{|c|c|c|c|c|c|c|c|c|c|c|c|c|c|}
\hline \multirow[t]{2}{*}{ Year } & \multirow{2}{*}{ 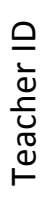 } & \multicolumn{2}{|c|}{$\begin{array}{l}\text { Revisiting } \\
\text { disposition }\end{array}$} & \multicolumn{2}{|c|}{$\begin{array}{l}\text { Visits to } \\
\text { static } \\
\text { illustration }\end{array}$} & \multicolumn{2}{|c|}{$\begin{array}{c}\text { Visits to } \\
\text { dynamic } \\
\text { visualization }\end{array}$} & \multicolumn{2}{|c|}{$\begin{array}{l}\text { Distributing } \\
\text { disposition }\end{array}$} & \multicolumn{2}{|c|}{$\begin{array}{l}\text { Days visited } \\
\text { static } \\
\text { illustration }\end{array}$} & \multicolumn{2}{|c|}{$\begin{array}{c}\text { Days visited } \\
\text { dynamic } \\
\text { visualization }\end{array}$} \\
\hline & & $M$ & SD & $M$ & SD & $M$ & SD & $M$ & SD & $M$ & SD & $M$ & SD \\
\hline 2010 & 0 & 1.97 & 0.57 & 1.31 & 0.98 & 3.73 & 2.86 & 1.18 & 0.33 & 1.18 & 0.77 & 1.94 & 1.28 \\
\hline 2010 & 1 & 1.76 & 0.24 & 1.25 & 0.51 & 3.64 & 1.98 & 1.10 & 0.11 & 1.05 & 0.23 & 1.46 & 0.5 \\
\hline 2010 & 2 & 1.8 & 0.56 & 1.32 & 0.83 & 3.08 & 2.15 & 1.11 & 0.32 & 1.11 & 0.52 & 1.61 & 0.8 \\
\hline 2010 & 3 & 1.78 & 0.4 & 1.40 & 0.62 & 3.40 & 2.77 & 1.16 & 0.11 & 1.07 & 0.25 & 1.2 & 0.41 \\
\hline 2011 & 0 & 2.15 & 0.56 & 1.21 & 0.49 & 3.04 & 2.67 & 1.00 & 0.14 & 1.06 & 0.31 & 1.32 & 0.77 \\
\hline 2011 & 1 & 2.54 & 0.59 & 5.95 & 2.67 & 9.27 & 4.15 & 1.40 & 0.22 & 2.49 & 0.74 & 2.53 & 0.79 \\
\hline 2011 & 2 & 1.56 & 0.44 & 1.60 & 1.01 & 2.88 & 2.09 & 0.89 & 0.42 & 1.25 & 0.59 & 1.69 & 0.92 \\
\hline 2011 & 4 & 2.29 & 0.74 & 3.36 & 2.23 & 6.5 & 4.25 & 1.39 & 0.38 & 2 & 0.86 & 2.21 & 0.96 \\
\hline 2011 & 5 & 1.56 & 0.21 & 3.90 & 1.82 & 5.76 & 3.26 & 0.97 & 0.10 & 2 & 0.38 & 2 & 0 \\
\hline 2011 & 6 & 1.46 & 0.3 & 1.15 & 0.66 & 2.28 & 1.86 & 0.98 & 0.15 & 1.01 & 0.31 & 1.07 & 0.39 \\
\hline
\end{tabular}


(2015). Revisiting for retention: An analytic for inquiry science learning. Journal of Learning Analytics, 2(2), 75-101. http://dx.doi.org/10.18608/jla.2015.22.7

\subsection{Regression Modelling of Revisiting Practices}

We initially modelled delayed post-test scores using Hierarchical Linear Modelling (HLM), but the number of participants was too low due to missing data. Calculations of intra-class correlation indicated that less than $5 \%$ of the variance in delayed scores was explained by clustering. Other research has suggested that in such cases, multi-level modelling is not warranted (Lee, 2000). Based on these findings, we proceeded with ordinary least squares regression modelling.

We know from prior work that students need sufficient time to develop coherent understanding of complex phenomena like climate change. We therefore first modelled retention using time spent on the unit. We tested various contextual variables (e.g., gender, teacher, school) not detailed here. We found that they did not explain significant variance.

We proceeded to add, then remove, the revisiting variables stepwise, resulting in four models that tested revisiting:

- Model 2: Revisiting disposition;

- Model 3: Revisiting the static illustration and dynamic visualization;

- Model 4: Distributing disposition;

- Model 5: Distributed revisiting of the static illustration and dynamic visualization.

Adding all variables at once would have resulted in multicollinearity, as the step-specific variables would not have explained variability not already explained by the disposition variables. Collinearity tolerances ranged from .56 to .85 , suggesting that although the number of total visits to the two specific steps $(r=.59)$ and number of days the specific steps were visited $(r=.57)$ were significantly correlated to each other, this was not an issue in the stepwise approach.

\section{RESULTS OF REGRESSION MODELLING}

A simple linear regression was calculated to predict delayed post-test scores based on duration of instruction ( $M=198$ minutes, $S D=65$ minutes). The delayed post-test score had a mean of 12.88 across classes and a standard deviation of 2.06. A significant regression equation was found $(F(1,662)=12.99$, $p<.001$ ) (Model 1, Table 5, Figure 5). Spending more time on the unit in total predicted higher scores on the delayed post-test, with an increase in the delayed post-test score of .004 for each additional minute spent. This was statistically significant but accounted for a small amount of variance in delayed post-test scores, $r^{2}=.02, p<.05$. 
(2015). Revisiting for retention: An analytic for inquiry science learning. Journal of Learning Analytics, 2(2), 75-101. http://dx.doi.org/10.18608/jla.2015.22.7

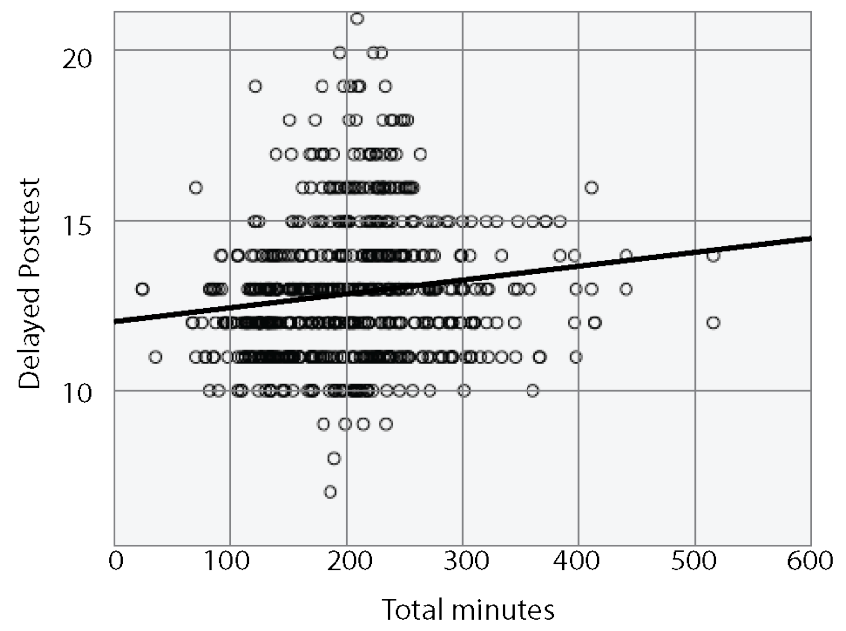

Figure 5. Scatterplot showing the relationship between total time spent on the unit and scores on the delayed post-test. Trend line shows $r^{2}=.19$.

In Model 2, a multiple linear regression was calculated to predict delayed post-test scores based on duration of instruction and revisiting disposition (general propensity to revisit steps, both across and within days, $M=1.81, S D=0.57)$. A significant regression equation was found $(F(2,661)=7.82, p<.001)$ (Model 2, Table 5). Spending more time on the unit in total predicted higher scores on the delayed posttest, with an increase in the delayed post-test score as before. Propensity to revisit was not a significant predictor. Model 2 did not explain significantly more variance in delayed post-test scores than Model 1 , $r^{2}=.022, p>.05$.

In Model 3, a multiple linear regression was calculated to predict delayed post-test scores based on duration of instruction and propensity to revisit specific steps (static illustration: $M=1.82, S D=1.80$; dynamic visualization: $M=3.59, S D=3.16)$, both across and within days. A significant regression equation was found $(F(3,660)=5.89, p<.001$ ) (Model 3, Table 5). Spending more time on the unit in total predicted higher scores on the delayed post-test, with an increase in the delayed post-test score as before. Each additional visit to the static illustration predicted a decrease in the delayed post-test score of 0.119. Additional visits to the dynamic visualization were not a significant predictor. Model 3 did not explain significantly more variance in delayed post-test scores than Model $1, r^{2}=.026, p>.05$.

In Model 4, a multiple linear regression was calculated to predict delayed post-test scores based on the duration of instruction and distributing disposition (general propensity to revisit steps across days, $M=1.13, S D=0.26)$. A significant regression equation was found $(F(2,661)=7.34, p<.001)$ (Model 4 , Table $5)$. Spending more time on the unit in total predicted higher scores on the delayed post-test, with an increase in the delayed post-test score as before. Propensity to distribute study by revisiting steps across days was not a significant predictor. Model 4 did not explain significantly more variance in delayed posttest scores than Model $1, r^{2}=.022, p>.05$. 
(2015). Revisiting for retention: An analytic for inquiry science learning. Journal of Learning Analytics, 2(2), 75-101. http://dx.doi.org/10.18608/jla.2015.22.7

In Model 5, a multiple linear regression was calculated to predict delayed post-test scores based on duration of instruction and propensity to distribute study by revisiting specific steps (static illustration: $M=1.27, S D=0.66$; dynamic visualization: $M=1.54, S D=0.86$ ) across days. A significant regression equation was found $(F(3,660)=10.59, p<.001$ ) (Model 5, Table 5). Spending more time on the unit in total predicted higher scores on the delayed post-test, with an increase in the delayed post-test score as before. Each additional visit to the static curriculum step predicted a decrease in the delayed post-test score of 0.534. Each additional visit to the dynamic curriculum step predicted an increase in the delayed post-test score of 0.430 . Model 5 explained significantly more variance in the delayed post-test scores than Model 1, $r^{2}=.046, p<.05$.

Table 5. Models of scores on the delayed post-test

\begin{tabular}{|c|c|c|c|c|}
\hline & \multicolumn{2}{|c|}{ Unstandardized Coefficients } & \multirow{2}{*}{$\begin{array}{c}\text { Standardized } \\
\text { Coefficients } \\
\beta\end{array}$} & \multirow[b]{2}{*}{$\mathrm{t}$} \\
\hline & B & Std. Error & & \\
\hline \multicolumn{5}{|c|}{ Model 1: Delayed post-test scores as a function of total time spent on the unit } \\
\hline Intercept & 12.084 & 0.238 & & $50.67 * *$ \\
\hline Total minutes for unit & 0.004 & 0.001 & .139 & $3.60 * *$ \\
\hline \multicolumn{5}{|c|}{$\begin{array}{c}\text { Model 2: Delayed post-test scores as a function of total time spent on the unit and revisiting } \\
\text { disposition }\end{array}$} \\
\hline Intercept & 12.224 & 0.257 & & $47.61 * *$ \\
\hline Total minutes for unit & 0.004 & 0.001 & .128 & $3.28 * *$ \\
\hline $\begin{array}{l}\text { Average number of times } \\
\text { each dyad visited steps } \\
\text { across the unit }\end{array}$ & -0.301 & 0.186 & -.083 & -1.62 \\
\hline \multicolumn{5}{|c|}{ Model 3: Delayed post-test scores as a function of total time spent on the unit and revisiting speci } \\
\hline Intercept & 12.07 & 0.238 & & $50.69 * *$ \\
\hline Total minutes for unit & 0.005 & 0.001 & .156 & $3.69 * *$ \\
\hline $\begin{array}{l}\text { Total number of visits to } \\
\text { static curriculum step }\end{array}$ & -0.119 & 0.055 & -.104 & $-2.15^{*}$ \\
\hline $\begin{array}{l}\text { Total number of visits to } \\
\text { dynamic visualization step }\end{array}$ & 0.035 & 0.032 & .054 & 1.11 \\
\hline \multicolumn{5}{|c|}{$\begin{array}{c}\text { Model 4: Delayed post-test scores as a function of total time spent on the unit and distributing } \\
\text { disposition }\end{array}$} \\
\hline Intercept & 12.420 & 0.352 & & $35.24 * *$ \\
\hline Total minutes for unit & 0.005 & 0.001 & .174 & $3.69 * *$ \\
\hline
\end{tabular}


(2015). Revisiting for retention: An analytic for inquiry science learning. Journal of Learning Analytics, 2(2), 75-101. http://dx.doi.org/10.18608/jla.2015.22.7

Average number of days

each dyad visited each

$-0.479$

0.371

$-.061$

$-1.29$

step

Model 5: Delayed post-test scores as a function of total time spent on the unit and distributing visits to specific steps

$\begin{array}{lcccc}\text { Intercept } & 12.151 & 0.251 & & 48.50^{* *} \\ \text { Total minutes for unit } & 0.004 & 0.001 & .130 & 3.15^{* *} \\ \text { Number of days visited } & -0.534 & 0.145 & -.172 & -3.67^{* *} \\ \begin{array}{l}\text { static curriculum step } \\ \text { Number of days visited }\end{array} & 0.430 & 0.113 & .180 & 3.80^{* *} \\ \text { dynamic visualization step } & & & .180\end{array}$

Model $1 r^{2}=.019, r^{2}$ change**; Model $2 r^{2}=.023, r^{2}$ change NS; Model 3 (compared to Model 1$) r^{2}=$ $.026, r^{2}$ change NS; Model 4 (compared to Model 1) $r^{2}=.022, r^{2}$ change NS; Model $5 r^{2}=.046, r^{2}$ change**; * Significant at $p<.05 ; * *$ Significant at $p<.01$

\section{DISCUSSION}

Our results are anchored to the realities of doing research in naturalistic classrooms. Our findings are correlational in nature, and reflect the messiness and complexities of doing research for and with complex science learning in public school settings. In such settings, teachers provide varied instructional supports outside the learning design, with some teachers allowing the learning design to do most of the work, others creating worksheets based on the learning design, and others creating entire labs to complement what students are learning. Teachers implement the learning design and associated measures according to schedules that they themselves may not have much control over as other testing and school events intercede. These challenges prevent strict experimental control, particularly for longer timescale interventions, yet it is important to study such interventions under real-world conditions.

Using automatically collected log data still provides an excellent opportunity to pose theoretically driven research questions about learning, even under these conditions. However, results from such approaches are correlational in nature, and cannot rule out the possibility that some undetected variable might cause both the behaviour and the outcome.

We took advantage of the log file data to test questions related to self-directed learning behaviours, namely, the amount of time a student spent studying the unit overall and various types of revisiting. In our study, the learning gains were modest, overall. Results across models show an advantage for longer time spent learning the unit, consistent with greater opportunity to learn the material. In our analysis, we found a small effect for duration of instruction. This is consistent with the value of spending more time on complex, inquiry activities documented in earlier studies of implementation of WISE units (Lee, 
(2015). Revisiting for retention: An analytic for inquiry science learning. Journal of Learning Analytics, 2(2), 75-101. http://dx.doi.org/10.18608/jla.2015.22.7

Linn, Varma, \& Liu, 2010). However, this finding is correlational. It may be that students who spend longer do so because they know how to make the extra time benefit their learning. Simply requiring students to spend longer might not result in increased gains, as students who have the propensity to spend less time, might spend time reviewing material shallowly or without purpose, resulting in little benefit for learning. Thus, understanding more about ways students direct their restudy behaviour could be useful in supporting learning and guiding learning designs.

Through a sequence of models, we tested various ways to operationalize revisiting as a metric: first, as a disposition to revisit in general; second, as a propensity to revisit specific material; third, as a disposition to distribute study over time; and fourth, as a propensity to distribute study of material over time. Revisiting previously studied materials is a compelling analytic because it is both theoretically grounded and relatively easy to detect. Prior research has shown that revisiting previously studied material - such as rereading a post in an online forum - can benefit learners (Wise, Hausknecht, \& Zhao, 2014), and that repeated retrieval supports retention (Karpicke \& Roediger, 2007). Likewise, repeated practice across days and over time supports learning (Andergassen et al., 2014; Mödritscher et al., 2013). Our findings tell a more complicated story, suggesting that revisiting may not be as straightforward an analytic as one might hope. Past research has shown that students differ in their propensity to update their memories (Bjork, 1978), and can judge when it is advantageous to distribute their learning over time (Popham, 2009). Our sequence of models suggests that having a disposition to revisit previously studied material - whether with a lag between sessions or not - might not explain variance in retention.

By testing a sequence of models that operationalized revisiting in different general and specific ways aligned to research on the value of distributed learning and a learning design, we were able to show that, as predicted, only distributed restudy of specific material supported retention. We found that while revisiting a dynamic visualization supported retention, revisiting a static illustration did not. In general, students visited the dynamic visualization with greater frequency and variability than they visited the static illustration, both in general and in a distributed (across days) manner. Overall, they visited the dynamic visualization nearly twice as often, suggesting a general perception that learning from the dynamic visualization required more visits. Alternatively, this could mean that students simply enjoyed playing with the dynamic visualization, and returned to it because of that. Students also spent more time per visit on the dynamic visualization $(M=134$ seconds, $S D=119)$ than the static illustration $(M=42$ seconds, $S D=33)$. These findings are not surprising as the dynamic visualization takes time to use and interact with in order to access the information it contains. Further, the dynamic visualization contained additional information, relating energy transformation to global temperature, a detail not present in the static illustration.

This detail is important as it highlights that this comparison is not intended to support inferences about the relative value of dynamic versus static visualizations in general. In fact, we stand by the decision to 
(2015). Revisiting for retention: An analytic for inquiry science learning. Journal of Learning Analytics, 2(2), 75-101. http://dx.doi.org/10.18608/jla.2015.22.7

include the static illustration, as our previous research has demonstrated that it supported students to connect their prior experiences and ideas and supported initial learning of a relatively abstract concept (Svihla \& Linn, 2012a). In our sample, distributed restudy of the dynamic visualization positively benefited retention, whereas more frequent revisiting, in general or across days, of the static illustration predicted lower retention. We discuss this finding grounded in the Knowledge Integration framework. Revisiting the dynamic visualization is likely to elicit Knowledge Integration activities, such as distinguishing among alternative ideas and linking ideas. This is not simply because it is a dynamic, as opposed to static, visualization, but also because it contains more complex information that cannot be accessed without interacting with the visualization. Students had previously made observations with the dynamic visualization, using it to test their predictions and initial ideas. When revisiting, the dynamic visualization could cue memories of these, or students could conduct further tests, leading to new observations or new insights. These afford students the opportunity to evaluate their understanding and make new links between ideas across activities. The significant advantage of revisiting the dynamic visualization is consistent with evidence for their value when they are implemented with guidance in online units (McElhaney \& Linn, 2011; Ryoo \& Linn, 2012; Svihla \& Linn, 2012a), and also consistent with a differentiation between simple recalling and more effortful relearning (Rawson \& Dunlosky, 2011).

However, it is important to note that pre-existing differences, such as in students' prior knowledge, their understanding of dynamic visualizations, as well as other factors may have led some students and not others to distribute their revisits across the different types of resources. Students who did not really develop understanding from their initial work with the interactive simulation might not have been predisposed to revisit it, relying instead on the easier to understand static visualization. Future research should investigate such variables under varied conditions to determine whether forced revisiting produces benefits for those who lack the propensity to revisit.

The significant disadvantage for revisiting the static illustration is consistent with evidence that when students reread text, often adding multi-coloured underlining, they do not succeed as well as their peers who test themselves on the material or seek links among ideas in the instructional materials (Bjork \& Bjork, 2009). These results resonate with other studies showing that durable, integrated understanding requires active integration of diverse ideas rather than recall of details (Bransford, Brown, \& Cocking, 2000; Linn \& Eylon, 2011) and benefits from self-monitoring ability (White \& Frederiksen, 1998). In addition, these results are consistent with research on spontaneous generation of explanations during learning. Based on our findings, more research is needed to understand how to design supports that encourage deliberate revisiting when learners are permitted to distribute their own practice.

Findings also suggest that students who choose to revisit deceptively clear or less demanding information, such as the metaphor for energy transformation rather than more complex and difficult to interpret ideas in dynamic visualizations, do not monitor their own learning effectively. While we believe that the metaphor supported students to develop an initial understanding of energy transformation, we 
(2015). Revisiting for retention: An analytic for inquiry science learning. Journal of Learning Analytics, 2(2), 75-101. http://dx.doi.org/10.18608/jla.2015.22.7

also think that an overreliance on this simple explanation did not support students to develop coherent, integrated, durable understandings of climate change. Further research is needed to understand how to support students to focus their energies on restudying materials that create desirable difficulties; such activities may make learning more effortful, but they also make it more durable.

Ultimately, the variables in Model 5 significantly predicted delayed post-test scores, but explained little variation in them. A number of other variables - e.g., pre- and post-assessments, student interest levels in the topic, other related instruction not documented by our system, differences in implementation that we lacked measures for - might have better predicted delayed post-test scores. However, the objective of our modelling was not to account for maximum variance in delayed post-test scores, but rather to explore nuanced models related to our research questions. We argue that although distributed revisiting of specific steps explained little variance, it is still an interesting metric. The amount of time accounted for by students' revisits to these two steps is small - a matter of only one or two minutes. That those minutes can explain any variability in scores on a test taken days to weeks later is surprising yet theoretically backed by an extensive research base on distributed learning.

\subsection{Limitations}

This research was conducted in classrooms in only three schools and used a single inquiry unit, limiting generalizability. We focused on Knowledge Integration and the findings might not generalize to other outcome measures or learning designs. Our design was comparative, lacking an experimental control; as such, our findings are tentative.

The relationships we found between revisiting and retention are correlational and could have been caused by some other unmeasured variable; for instance, there may be some systematic reason that lead certain students to revisit dynamic visualizations, and lead others to revisit static illustrations. For instance, teachers might have encouraged students they viewed as smarter to revisit the dynamic visualizations, and encouraged others to revisit the static illustrations. It is also possible that, like time on task, more adept students were better able to judge that revisiting the dynamic visualization would be helpful to their learning. Simply forcing students to revisit complex material does not mean they will know what to do with it. Future studies could investigate this through randomized, systematic comparisons, forcing some students to revisit material, and allowing others to direct their own revisiting. This would clarify whether the value of revisiting is in the revisit itself, or in the decision to revisit. Similarly, it would be helpful to better understand, through prompted recall or think-aloud protocol, more about how students make decisions to revisit specific materials. Alternatively, simple questions might be posed when a revisit to a particular step is detected, allowing students to reflect both on why they chose to revisit and whether they found it beneficial to do so. This could lead to new metrics that might differentiate between reasons for revisiting. This would provide guidance for the 
(2015). Revisiting for retention: An analytic for inquiry science learning. Journal of Learning Analytics, 2(2), 75-101. http://dx.doi.org/10.18608/jla.2015.22.7

creation of learning designs that aim to encourage students to make the decision to revisit specific material, rather than forcing them down a particular path.

We defined revisiting based on activities detected in log files. Students could engage in other forms of revisiting that our methods do not document. For instance, teachers in some classes may have retaught information, or provided study sheets and additional assessments covering related content.

Although we found variables that could significantly predict the variability of delayed post-test scores, other explanations should be entertained. For instance, the finding that spending longer on the unit predicted higher scores could be a reflection of some other unmeasured variable, such as differences in student persistence, or in teachers' expectations of individual students. Thus, although this finding mirrors previous research, it should not be viewed as a prescriptive that more time is necessarily better. Likewise, there may be other explanations for why students revisit a particular step; they may be prompted by a teacher based on a conversation not shared across the class, meaning that the conversation itself may have produced the benefit, rather than the opportunity to restudy.

\subsection{Implications}

Combining learning analytics with learning design has previously helped guide the analysis of and refinement of learning designs in learning management systems (Wise, 2014; Wise, Saghafian, \& Padmanabhan, 2012). This combination allows researchers to plan and test learning designs guided by theories of learning (Lockyer et al., 2013; Wise, 2014).

Our sequence of models focused on retention, as opposed to initial learning, and this has implications for learning designers who wish to incorporate revisiting as a learning analytic. First, based on research on distributed learning, it is likely that the benefit of revisiting may not be visible on an immediate posttest (Rohrer \& Taylor, 2006). This means that detecting benefits on retention requires longer-term investments in the study sites. This can present challenges, especially for researchers working in schools already beleaguered by the amount of testing. Such settings may prevent researchers from implementing a delayed post-test, and therefore would present a barrier to furthering this work.

We found that revisiting is a promising yet complex learning analytic for predicting retention of coherent understanding of complex scientific phenomena. Its value as an analytic was increased by theoretical guidance for what is revisited. While revisiting as a broad, generic metric did not predict retention, a more nuanced approach to revisiting did. This metric aligns with the Knowledge Integration framework, in that revisiting dynamic visualizations better supports the kind of effortful relearning needed for coherent understanding and retention of complex scientific phenomena.

The greater variability in visits to the dynamic visualization, compared to the static illustration, suggests implications for instructors and for learning designers working with analytics. Not all students 
(2015). Revisiting for retention: An analytic for inquiry science learning. Journal of Learning Analytics, 2(2), 75-101. http://dx.doi.org/10.18608/jla.2015.22.7

recognized the need to restudy the complex information in the dynamic visualization. Although tentative, our findings suggest that there may be a benefit to prompting students to restudy such material, either by the instructor or by the learning management system. Further research is needed to contrast the relative benefits from spontaneous and prompted restudy, however, as prompted restudy may not have the same effect.

Revisiting is a valuable and relatively easy to detect analytic for retention that could be applied to other contexts; however, it should be applied in a nuanced manner, informed by the theory of learning guiding the learning design.

The finding that generic revisiting - even distributed across days - did not significantly predict retention suggests two implications for learning designers using learning analytics. The first is promising, in that it suggests that a general disposition to revisit, something learning designers have little control over, might not be that important as a concern. However, without an additional measure of revisiting as a disposition, this should be treated as tentative and explored further in other settings. The second implication is that a nuanced design and definition of revisiting is likely needed and likely contextual. Generic restudy of all material - a common instructional approach we observed in classrooms - may not be as beneficial for retention as one would hope. Yet, this suggests that there is much more work to be done to understand how to apply revisiting as an analytic in specific learning designs, and this study contributes and contrasts a range of ways to do so.

Given the relatively brief time required to prompt and carry out distributed restudy, either as an instructor or as a learning designer, our findings suggest it may be a worthwhile investment. However, one of the lessons from our sequence of models is that not all revisiting is equally capable of predicting retention. Understanding how to incorporate findings from the research on distributed learning into a specific learning design, and further how to use revisiting as an analytic appears to require a nuanced understanding of both the theory and the learning design. Based on our findings, we encourage instructors and learning designers to focus the efforts of distributed restudy on the most central and complex material in their learning designs.

The potential of revisiting as an analytic, at least as we have conceptualized and studied it, is most promising for learning theories that address long-term and longitudinal approaches to learning. We see potential in using such analytics to guide the learning designs that, for instance, support learning progressions (Duncan \& Hmelo-Silver, 2009; Gunckel, Mohan, Covitt, \& Anderson, 2012; Shin \& Stevens, 2012) and curricular standards based (at least in part) on them (e.g., NGSS Lead States, 2013; National Governors Association Center for Best Practices, \& Council of Chief State School Officers, 2010). In such contexts, revisiting as an analytic could help refine learning theory and learning designs by helping researchers maintain focus on both initial learning supports and longer-term retention. 
(2015). Revisiting for retention: An analytic for inquiry science learning. Journal of Learning Analytics, 2(2), 75-101. http://dx.doi.org/10.18608/jla.2015.22.7

Adding analytic tools to learning designs like WISE could also help teachers pose, then monitor, longterm retention questions. Many of our teachers were interested in posing their own questions about the impact their instruction had when using WISE. They were curious, for instance, if a whole-class demo of an interactive visualization, after students had encountered it in pairs, could improve student retention. As many of them taught multiple sections, they sometimes ran informal comparisons, trying one approach with one section and another with another section. For instance, one teacher talked about using a simple starter prompt with one section, and revisiting a specific question from the learning design with another section. Integrated analytics tools could capitalize on this interest and help them structure meaningful investigations, including providing guidance to look beyond short-term gains. Such a suite of tools could include options to help teachers select central concepts they planned to guide students to revisit as well as those they observed students spontaneously revisiting, a set of prompts to encourage teachers to record notes about their instruction in room as a way to gather information not automatically recorded, and automatically computed scores for revisiting. Such tools could elevate teaching practice by supporting teachers to pursue more easily what might otherwise be fleeting curiosities.

\section{ACKNOWLEDGMENTS}

Though funded by the NSF (Grant \#0822388), the views expressed here are not necessarily those of the NSF. Support was also provided by a grant from the first two authors' institution. We would like to acknowledge the teachers and students who participated in this research, and express thanks to other members of the research group for their feedback. We also want to thank the anonymous reviewers whose comments helped us craft a much stronger manuscript.

\section{REFERENCES}

Andergassen, M., Mödritscher, F., \& Neumann, G. (2014). Practice and repetition during exam preparation in blended learning courses: Correlations with learning results. Journal of Learning Analytics, 1(1), 48-74. Retrieved from https://epress.lib.uts.edu.au/journals/index.php/JLA/article/view/3254

Barbera, E., \& Reimann, P. (2013). Assessment and evaluation of time factors in online teaching and learning. Hershey, PA: IGI Global.

Bird, S. (2010). Effects of distributed practice on the acquisition of second language English syntax. Applied Psycholinguistics, 31(4), 635-650. http://dx.doi.org/10.1017/S0142716410000172

Bjork, E. L., \& Bjork, R. (2009). Making things hard on yourself, but in a good way: Creating desirable difficulties to enhance learning. New York: Worth Publishers.

Bjork, R. A. (1978). The updating of human memory. In G. H. Bower (Ed.), The psychology of learning and motivation (Vol. 12, pp. 235-259). New York: Academic Press. 
(2015). Revisiting for retention: An analytic for inquiry science learning. Journal of Learning Analytics, 2(2), 75-101. http://dx.doi.org/10.18608/jla.2015.22.7

Bloom, K. C., \& Shuell, T. J. (1981). Effects of massed and distributed practice on the learning and retention of second-language vocabulary. The Journal of Educational Research, 74(4), 245-248. http://dx.doi.org/10.1080/00220671.1981.10885317

Bransford, J. D., Brown, A. L., \& Cocking, R. R. (Eds.). (2000). How people learn: Brain, mind, experience, and school. Expanded edition. Washington, DC: National Academy Press.

Budé, L., Imbos, T., Wiel, M. W., \& Berger, M. P. (2011). The effect of distributed practice on students' conceptual understanding of statistics. Higher Education, 62(1), 69-79. http://dx.doi.org/10.1007/s10734-010-9366-y

Carpenter, S. K., Cepeda, N. J., Rohrer, D., Kang, S. H. K., \& Pashler, H. (2012). Using spacing to enhance diverse forms of learning: Review of recent research and implications for instruction. Educational Psychology Review, 24(3), 369-378. http://dx.doi.org/10.1007/s10648-012-9205-z

Carpenter, S. K., \& Pashler, H. (2007). Testing beyond words: Using tests to enhance visuospatial map learning. Psychonomic Bulletin \& Review, 14(3), 474-478. http://dx.doi.org/10.3758/BF03194092

Carpenter, S. K., Pashler, H., \& Cepeda, N. J. (2009). Using tests to enhance 8th grade students' retention of US history facts. Applied Cognitive Psychology, 23(6), 760-771. http://dx.doi.org/10.1002/acp.1507

Cepeda, N. J., Pashler, H., Vul, E., Wixted, J. T., \& Rohrer, D. (2006). Distributed practice in verbal recall tasks: A review and quantitative synthesis. Psychological Bulletin, 132(3), 354-380.

Chi, M. T. H., Bassok, M., Lewis, M. W., Reimann, P., \& Glaser, R. (1989). Self-explanations: How students study and use examples in learning to solve problems. Cognitive Science: A Multidisciplinary Journal, 13(2), 145-182. http://dx.doi.org/10.1207/s15516709cog1302_1

Chiu, J. L. (2010). Supporting students' knowledge integration with technology-enhanced inquiry curricula (Unpublished doctoral dissertation, UMI No. AAT 3413337). University of California, Berkeley.

Cook, M. P. (2006). Visual representations in science education: The influence of prior knowledge and cognitive load theory on instructional design principles. Science Education, 90(6), 1073-1091. http://dx.doi.org/10.1002/sce.20164

Cotton, K. (1990). Educational time factors. Portland, OR: Northwest Regional Educational Laboratory

Delaney, P. F., Verkoeijen, P. P. J. L., \& Spirgel, A. (2010). Spacing and testing effects: A deeply critical, lengthy, and at times discursive review of the literature. Psychology of Learning and Motivation, 53, 63-147. http://dx.doi.org/10.1016/S0079-7421(10)53003-2

Donovan, J. J., \& Radosevich, D. J. (1999). A meta-analytic review of the distribution of practice effect: Now you see it, now you don't. Journal of Applied Psychology, 84(5), 795-805.

Duncan, R., \& Hmelo-Silver, C. (2009). Learning progressions: Aligning curriculum, instruction, and assessment. Journal for Research in Science Teaching, 46(6), 606-609. http://dx.doi.org/10.1002/tea.20316 
(2015). Revisiting for retention: An analytic for inquiry science learning. Journal of Learning Analytics, 2(2), 75-101. http://dx.doi.org/10.18608/jla.2015.22.7

Dunlosky, J., \& Rawson, K. A. (2012). Despite their promise, there's still a lot to learn about techniques that support durable learning. Journal of Applied Research in Memory and Cognition, 1(4), 254256. http://dx.doi.org/10.1016/j.jarmac.2012.10.003

Ferguson, R. (2012). Learning analytics: Drivers, developments and challenges. International Journal of Technology Enhanced Learning, 4(5), 304-317. http://dx.doi.org/10.1504/IJTEL.2012.051816

Gunckel, K. L., Mohan, L., Covitt, B. A., \& Anderson, C. W. (2012). Addressing challenges in developing learning progressions for environmental science literacy. In A. C. Alonzo \& A. Wenk Gotwals (Eds.), Learning progressions in science (pp. 39-75). Rotterdam: Sense Publishers.

Hegarty, M. (2004). Dynamic visualizations and learning: Getting to the difficult questions. Learning and Instruction, 14(3), 343-352. http://dx.doi.org/10.1016/j.learninstruc.2004.06.007

Höffler, T., \& Leutner, D. (2007). Instructional animation versus static pictures: A meta-analysis. Learning and Instruction, 17(6), 722-738. http://dx.doi.org/10.1016/j.learninstruc.2007.09.013

Janiszewski, C., Noel, H., \& Sawyer, A. G. (2003). A meta-analysis of the spacing effect in verbal learning: Implications for research on advertising repetition and consumer memory. Journal of Consumer Research, 30(1), 138-149. http://dx.doi.org/10.1086/374692

Kali, Y. (2006). Collaborative knowledge building using the design principles database. International Journal of Computer-Supported Collaborative Learning, 1(2), 187-201. http://dx.doi.org/10.1007/s11412-006-8993-x

Kali, Y., Linn, M. C., \& Roseman, J. (2008). Designing coherent science education: Implications for curriculum, instruction, and policy. New York: Teachers College, Columbia University.

Karpicke, J. D., \& Roediger, H. L., III. (2007). Repeated retrieval during learning is the key to long-term retention. Journal of Memory and Language, 57(2), 151-162. http://dx.doi.org/10.1016/j.jml.2006.09.004

Kerfoot, B. P., Kearney, M. C., Connelly, D., \& Ritchey, M. L. (2009). Interactive spaced education to assess and improve knowledge of clinical practice guidelines: A randomized controlled trial. Annals of Surgery, 249(5), 744-749. http://dx.doi.org/10.1097/SLA.0b013e31819f6db8

Kornell, N., Castel, A., Eich, T., \& Bjork, R. A. (2010). Spacing as the friend of both memory and induction in young and older adults. Psychology and Aging, 25(2), 498-503. http://dx.doi.org/10.1037/a0017807

Laurillard, D. (2012). The learning designer: Supporting teaching as a design science. In R. Ørngreen (Ed.), Proceedings of the Third Designs for Learning Conference (Dfl2012) (p. 11). Copenhagen: Aalborg University.

Retrieved from http://pure.au.dk/portal/files/45188015/DfL2012_Conference_Proceedings.pdf

Lee, H.-S., Linn, M. C., Varma, K., \& Liu, O. L. (2010). How do technology-enhanced inquiry science units impact classroom learning? Journal of Research in Science Teaching, 47(1), 71-90. http://dx.doi.org/10.1002/tea.20304

Lee, V. (2000). Using hierarchical linear modeling to study social contexts: The case of school effects. Educational Psychologist, 35(2), 125-141. http://dx.doi.org/10.1207/S15326985EP3502_6 
(2015). Revisiting for retention: An analytic for inquiry science learning. Journal of Learning Analytics, 2(2), 75-101. http://dx.doi.org/10.18608/jla.2015.22.7

Linn, M. C. (2006). The knowledge integration perspective on learning and instruction. In K. Sawyer (Ed.), The Cambridge handbook of the learning sciences (pp. 243-264). New York: Cambridge University Press.

Linn, M. C., \& Eylon, B.-S. (2011). Science learning and instruction: Taking advantage of technology to promote knowledge integration. New York: Routledge.

Liu, O. L., Lee, H., Hofstetter, C., \& Linn, M. C. (2008). Assessing knowledge integration in science: Construct, measures, and evidence. Educational Assessment, 13(1), 33-55. http://dx.doi.org/10.1080/10627190801968224

Liu, O. L., Ryoo, K., Linn, M. C., Sato, E., \& Svihla, V. (2015). Measuring knowledge integration learning of energy topics: A two-year longitudinal study. International Journal of Science Education 37(7), 1044-1066. http://dx.doi.org/10.1080/09500693.2015.1016470

Lockyer, L., Heathcote, E., \& Dawson, S. (2013). Informing pedagogical action: Aligning learning analytics with learning design. American Behavioral Scientist, 57(10), 1439-1459. http://dx.doi.org/ $10.1177 / 0002764213479367$

Marbach-Ad, G., Rotbain, Y., \& Stavy, R. (2008). Using computer animation and illustration activities to improve high school students' achievement in molecular genetics. Journal of Research in Science Teaching, 45(3), 273-292. http://dx.doi.org/10.1002/tea.20222

McElhaney, K. W., \& Linn, M. C. (2011). Investigations of a complex, realistic task: Intentional, unsystematic, and exhaustive experimenters. Journal of Research in Science Teaching, 48(7), 745-770. http://dx.doi.org/10.1002/tea.20423

Mödritscher, F., Andergassen, M., \& Neumann, G. (2013). Dependencies between e-learning usage patterns and learning results. Proceedings of the 13th International Conference on Knowledge Management and Knowledge Technologies (i-KNOW '13), (Article No. 24). http://dx.doi.org/10.1145/2494188.2494206

National Governors Association Center for Best Practices, \& Council of Chief State School Officers. (2010). Common core state standards for mathematics. Washington, D.C.: Authors.

NGSS Lead States. (2013). Next generation science standards: For states, by states. Retrieved on October 10, 2015 from http://www.nextgenscience.org/

Popham, W. J. (2009). Assessment literacy for teachers: Faddish or fundamental? Theory into Practice, 48(1), 4-11. http://dx.doi.org/10.1080/00405840802577536

Rawson, K. A. (2012). Why do rereading lag effects depend on test delay? Journal of Memory and Language, 66, 870-884. http://dx.doi.org/10.1016/j.jml.2012.03.004

Rawson, K. A., \& Dunlosky, J. (2011). Optimizing schedules of retrieval practice for durable and efficient learning: How much is enough? Journal of Experimental Psychology: General, 140(3), 283302.http://dx.doi.org/10.1037/a0023956

Rawson, K. A., \& Kintsch, W. (2005). Rereading effects depend on time of test. Journal of Educational Psychology, 97(1), 70-80. http://dx.doi.org/10.1037/0022-0663.97.1.70 
(2015). Revisiting for retention: An analytic for inquiry science learning. Journal of Learning Analytics, 2(2), 75-101. http://dx.doi.org/10.18608/jla.2015.22.7

Rea, C. P., \& Modigliani, V. (1985). The effect of expanded versus massed practice on the retention of multiplication facts and spelling lists. Human Learning: Journal of Practical Research \& Applications, 4(1), 11-18.

Reynolds, J. H., \& Glaser, R. (1964). Effects of repetition and spaced review upon retention of a complex learning task. Journal of Educational Psychology, 55(5), 297-308.

Roediger, H. L., III, \& Karpicke, J. (2006). Test-enhanced learning: Taking memory tests improves longterm retention. Psychological Science, 17(3), 249-255. http://dx.doi.org/10.1111/j.14679280.2006.01693.x

Rohrer, D., \& Taylor, K. (2006). The effects of overlearning and distributed practise on the retention of mathematics knowledge. Applied Cognitive Psychology, 20(9), 1209-1224.

Ryoo, K., \& Linn, M. C. (2010). Student progress in understanding energy concepts in photosynthesis using interactive visualizations. In K. Gomez, L. Lyons, J. Radinsky (Eds.), Learning in the Disciplines: Proceedings of the 9th International Conference of the Learning Sciences (ICLS 2012) (Vol. 2, pp. 480-481). Chicago: ISLS.

Ryoo, K., \& Linn, M. C. (2012). Can dynamic visualizations improve middle school students' understanding of energy in photosynthesis? Journal of Research in Science Teaching, 49(2), 218243. http://dx.doi.org/10.1002/tea.21003

Seabrook, R., Brown, G., \& Solity, J. (2005). Distributed and massed practice: From laboratory to classroom. Applied Cognitive Psychology, 19(1), 107-122. http://dx.doi.org/10.1002/acp.1066

Shin, N., \& Stevens, S. Y. (2012). Development and validation of a scale to place students along a learning progression. In J. van Aalst, K. Thompson, M. J. Jacobson, P. Reimann (Eds.), The Future of Learning: Proceedings of the 10th International Conference of the Learning Sciences (ICLS 2012) (Vol. 2, pp. 396-400). Sydney, Australia: ISLS.

Slotta, J., \& Chi, M. (2006). The impact of ontology training on conceptual change: Helping students understand the challenging topics in science. Cognition and Instruction, 24(2), 261-289. http://dx.doi.org/10.1207/s1532690xci2402_3

Slotta, J., \& Linn, M. C. (2009). WISE science: Web-based inquiry in the classroom. New York: Teachers College Press.

Smith, S., \& Rothkopf, E. (1984). Contextual enrichment and distribution of practice in the classroom. Cognition and Instruction, 1(3), 341-358. http://dx.doi.org/10.1207/s1532690xci0103_4

Sobel, H. S., Cepeda, N. J., \& Kapler, I. V. (2010). Spacing effects in real world classroom vocabulary learning. Applied Cognitive Psychology, 25(5), 763-767. http://dx.doi.org/10.1002/acp.1747

Svihla, V., Gerard, L., Ryoo, K., Sato, E., Visintainer, T., Swanson, H., . . Dorsey, C. (2010). Energy across the curriculum: Cumulative learning using embedded assessment results. In K. Gomez, L. Lyons, J. Radinsky (Eds.), Learning in the Disciplines: Proceedings of the 9th International Conference of the Learning Sciences (ICLS 2012) (Vol. 2, pp. 257-259). Chicago, IL: ISLS.

Svihla, V., \& Linn, M. C. (2012a). A design-based approach to fostering understanding of global climate change. International Journal of Science Education, 34(5), 651-676. http://dx.doi.org/10.1080/09500693.2011.597453 
(2015). Revisiting for retention: An analytic for inquiry science learning. Journal of Learning Analytics, 2(2), 75-101. http://dx.doi.org/10.18608/jla.2015.22.7

Svihla, V., \& Linn, M. C. (2012b). Distributing practice: Challenges and opportunities for inquiry learning. In J. van Aalst, K. Thompson, M. J. Jacobson, P. Reimann (Eds.), The Future of Learning: Proceedings of the 10th International Conference of the Learning Sciences (ICLS 2012) (Vol. 2, pp. 371-378). Sydney, Australia: ISLS.

Tversky, B., Morrison, J., \& Betrancourt, M. (2002). Animation: Can it facilitate? International Journal of Human Computer Studies, 57(4), 247-262. http://dx.doi.org/10.1006/ijhc.2002.1017

Vlach, H. A., \& Sandhofer, C. M. (2012). Distributing learning over time: The spacing effect in children's acquisition and generalization of science concepts. Child Development 83(4), 1137-1144. http://dx.doi.org/10.1111/j.1467-8624.2012.01781.x

West, S. L. (2011). Anglo and Hispanic college students' performance and intent to graduate: A prospective examination of risk factors in two theoretical models (Unpublished doctoral dissertation, Texas Tech University). Retrieved from Electronic Theses and Dissertations. Retrieved from http://hdl.handle.net/2346/21574

White, B. Y., \& Frederiksen, J. R. (1998). Inquiry, modeling, and metacognition: Making science accessible to all students. Cognition and Instruction, 16(1), 3-118. http://dx.doi.org/10.1207/s1532690xci1601_2

Wilensky, U., \& Reisman, K. (2006). Thinking like a wolf, a sheep, or a firefly: Learning biology through constructing and testing computational theories - an embodied modeling approach. Cognition and Instruction, 24(2), 171-209. http://dx.doi.org/10.1207/s1532690xci2402_1

Wise, A. F. (2014). Designing pedagogical interventions to support student use of learning analytics. Proceedings of the 4th International Conference on Learning Analytics and Knowledge (LAK '14), 203-211. http://dx.doi.org/10.1145/2567574.2567588

Wise, A. F., Hausknecht, S. N., \& Zhao, Y. (2014). Attending to others' posts in asynchronous discussions: Learners' online "listening" and its relationship to speaking. International Journal of ComputerSupported Collaborative Learning, 9(2), 185-209. http://dx.doi.org/10.1007/s11412-014-9192-9

Wise, A. F., Saghafian, M., \& Padmanabhan, P. (2012). Towards more precise design guidance: Specifying and testing the functions of assigned student roles in online discussions. Educational Technology Research and Development, 60(1), 55-82. http://dx.doi.org/10.1007/s11423-011-9212-7

Zhang, Z. H., \& Linn, M. C. (2011). Can generating representations enhance learning with dynamic visualizations? Journal of Research in Science Teaching, 48(10), 1177-1198. http://dx.doi.org/10.1002/tea.20443 